\title{
La constitucionalización del ordenamiento jurídico y del mundo de la vida social: el caso italiano y colombiano*
}

\author{
The constitutionalization of the legal organization and the world of social life: the \\ italian and colombian case
}

\author{
Adrian Zeballosf-Cuathin ** \\ EnRIQUe CÁCERES MendoZA***
}

*Este trabajo se desarrolla en el marco del proyecto de investigación titulado: "La eficacia de los derechos sociales, económicos y culturales en Colombia"

**Abogado, candidato a doctor en Derecho de la Universidad Nacional de Colombia. Docente investigador de la Facultad de Derecho y Ciencias Políticas y Sociales de la Universidad La Gran Colombia. Correo electrónico: adrian.zeballosf@ugc.edu.co

*** Abogado, candidato a Doctor. Docente de la Universidad Nacional de Colombia. Correo electrónico: aecaceresm@unal.edu.co.

Fecha de recepción: 30 septiembre de 2019 Fecha de aprobación: 30 de Noviembre de 2019

Para citar este artículo / To reference this article Zeballosf-Cuathin, A., y Cáceres, E. (2019) La constitucionalización del ordenamiento jurídico y del mundo de la vida social: el caso italiano y colombiano. Inciso, 21(2); $161-179$.

\section{Resumen}

El propósito de este trabajo es explicar la naturaleza jurídica de la institución denominada "constitucionalización del derecho", así como resaltar su importancia y alcance en el ordenamiento jurídico italiano y colombiano. Para cumplir tales fines, se adopta una metodología cualitativa a partir de la revisión y el análisis documental de referentes teóricos, junto con análisis comparado entre los modelos jurídicos -constitucionales de ambos países-, con base en doctrina actualmente existente, a fin de alcanzar, mediante un proceso lógico deductivo, algunas conclusiones propositivas sobre los progresos que la constitucionalización del derecho ha irradiado en todos los aspectos del mundo de la vida jurídica, de cara a retos y objetivos de las sociedades dinámicas. Concretamente se pudo establecer que la forma, materia y alcance de la constitucionalización del derecho en Italia y Colombia tiene diferencias importantes, en cuanto al modo y la intensidad del proceso de constitucionalización, pero aún así, mantienen patrones similares y comparten ciertos elementos o criterios comunes, sobre todo en la eficacia judicial de los derechos humanos y fundamentales. 
Palabras clave: Constitución, bloque de constitucionalidad, constitucionalización del derecho, Estado constitucional y convencional de derecho, Derechos Humanos.

\begin{abstract}
The porpuse of this work is explain the legal nature of the institution called "law constitutionalization", also to stand out it's importance and reach in the Italian and Colombian legal system. To comply those intensions, it's used a cualitative metodology starting with the revision and analysis of documents of theorical references, at the same time comparing the constitutional legal systems -of both countries-, based on actual and existent doctrine, pretending to reach, using a logical deductive process, some propositive conclutions about the progresses that the law constitutionalization have radiated to all the aspects of the legal life, facing the challenges and objectives from the dinamic societies. Specifically, the conclution is that the form, matter and scope of law constitutionalization in Italy and Colombia have important differences in the way and intensity of that process, but, nevertheless, the patrons are similar and share some elements or common aspects, especially in the legal effectiveness of the human and fundamental rights.
\end{abstract}

Keywords: Constitution, constitutional block, law constitutionalization, constitutional and conventional law state, human rights, fundamental rights, constitutional interpretation.

\title{
Introducción
}

Una de las transformaciones más importantes de los modelos jurídico - constitucionales contemporáneos ha sido, sin duda alguna, la superación del paradigma del dogmatismo jurídico positivista, que consideraba a la Constitución Política simplemente como una carta de buenas intenciones políticas, para pasar a convertirla en una realidad normativa, orientada a la formulación de soluciones jurídicas mucho más sistémicas, pero a la vez complejas, en torno a presupuestos de carácter axiológico, recopilados como valores, principos, derechos humanos y fundamentales, hoy visibles como marco general de acción para la toma de las decisiones judiciales.

Para Carlos Santiago Nino, el problema de la dogmática jurídica se queda en buena parte resumido en la insuficiencia material que las soluciones estrictamente legales prevén para situaciones concretas, siendo necesario, pues, abordar el derecho desde nuevas ópticas discursivas, en torno a la defensa de valores superiores que sustenten los sistemas democráticos, como derechos que los ciudadanos: "Deben reconocer recíprocamente si quieren regular de modo legítimo su convivencia mediante el derecho positivo" (Habermas citado por García Amado, 1993, p. 239), y que se convierten en paradigmas centrales en los nuevos sistemas jurídicos.

Después de las evidentes debilidades presentadas por los modelos positivistas que rendían culto a la ley, los parámetros de validez y eficacia del sistema jurídico empezaron a ser revaluados en función de nuevas problemáticas específicas, asociadas a la legitimidad y la justicia de las normas, habiéndose demostrado que el papel del legislador ya no era tan absoluto a la hora de plantear las discusiones sobre el alcance normativo y el papel de las autoridades públicas. Las transformaciones políticas, sociales, económicas y culturales de la segunda postguerra 
evidenciarían la necesidad de incorporar nuevos referentes en el espectro jurídico interno e internacional, y es allí en donde nace el neoconstitucionalismo como un nuevo eje discursivo, que se antoja como un sistema de amplio espectro normativo, pero también político, condicionante para las autoridades democráticas, y a la vez, como medio de garantía del respeto por los derechos fundamentales de los ciudadanos.

Con ocasión de lo anterior, el paradigma positivista del derecho se ve obligado a tomar nuevos referentes: la Constitución, como carta política y jurídica, se constituye entonces en el elemento por excelencia de los Estados democráticos de derecho y se le asigna un rol más cercano al común de la ciudadanía, se establecen amplios textos de reconocimiento de derechos individuales y colectivos, pero también se formulan mecanismos directos para su protección, fijando ahora límites concretos al accionar de los Estados, en torno a las garantías de carácter constitucional que pasan a condicionar todo el ordenamiento normativo, que al mismo tiempo sujetan el derecho interno a las prescripciones propias del Derecho Internacional de los Derechos Humanos, mediante figuras novedosas, como los bloques de constitucionalidad y de convencionalidad.

Rodrigo Uprimny sostiene, con razón, que la admisión de la idea del papel de la Constitución como norma superior y fundante de una sociedad democrática de derecho conduce inexorablemente a aceptar una progresiva constitucionalización de todo el ordenamiento jurídico, a su vez, establece la obligación de introducir la interpretación constitucional como regla número uno en la aplicación del ordenamiento (Uprimny, 2006), lo que supone, entonces, que el ordenamiento jurídico trasciende las simples reglas secundarias o de "adjudicación" para aceptar la prevalencia de reglas "de reconocimiento", a la par de valores y principios fundantes para ese modelo en particular de sociedad.

En este orden de ideas, el papel preponderante de los paradigmas constitucionales en relación con los principios, valores y reglas, obliga a redimensionar el sentido real del derecho, en la medida en que la actividad judicial debe no solo examinar el tradicional silogismo jurídico y subsumir los hechos a las previsiones abstractas del legislador, sino que debe ser más propositivo y crítico a la hora de tamizar las decisiones por el filtro de la Constitución, en torno a figuras como la acción o la excepción de inconstitucionalidad, que suponen la contravía directa entre la norma rasa y el valor fundante de rango constitucional.

Pues bien, este fenómeno al que se ha llegado como resultado de la incorporación de nuevos discursos jurídicos y políticos, no es otro que la llamada "Constitucionalización del Derecho", que supera las barreras estrictamente dogmáticas para hacer del derecho un sistema dinámico y cambiante, que gira hoy en torno a garantías, libertades, instrumentos de protección, derechos y valores de los Estados contemporáneos.

De conformidad con lo anterior, se formula la siguiente pregunta de investigación: ¿Cuál es la dimensión, en los ordenamientos jurídicos de Italia y Colombia, del fenómeno jurídico llamado constitucionalización del derecho? La pregunta así formulada exige una respuesta previa en el siguiente sentido: la constitucionalización del derecho en Italia y Colombia tiene características similares, aunque con diferencias importantes en cuanto al objeto, grado e intensidad. Con fundamento en la pregunta y en la hipótesis, enseguida se formula el siguiente objetivo general: explicar el alcance del fenómeno jurídico Ilamado "Constitucionalización del derecho", en los ordenamientos jurídicos mencionados. 
En un primer momento, se realizará una aproximación al concepto y la fundamentación de la constitucionalización del derecho, como fenómeno social y político, a propósito de sus orígenes y transformación, especialmente en Italia y Colombia. En un segundo momento, el análisis se centra en las consecuencias del proceso de constitucionalización, estableciendo que el efecto constitucional se abre a espacios pluridimensionales y complejos, que tocan elementos como el poder, la institucionalidad y el derecho. En un tercer momento, se hace referencia a algunas reflexiones sobre los resultados prácticos de tal fenómeno en las sociedades contemporáneas, principalmente a propósito de las experiencias comparadas de dos modelos jurídico constitucionales que se abordan en secciones diferentes: el modelo italiano y el modelo colombiano. Finalmente se comparten algunas conclusiones.

\section{El concepto de Constitucionalización del derecho y del mundo de la vida social}

La Constitución no tiene otra pretensión que moldear, definir y precisar cada uno de los sujetos y objetos que están bajo su imperio. En otras palabras, la Constitución se mueve en escenarios propios de la vida misma. Estas afirmaciones pueden dar cuenta a priori del fenómeno jurídico llamado constitucionalización del derecho y del mundo de la vida social.

Esta institución jurídica hace que su poder irradie no solamente las normas que se encuentran subordinadas a ella, sino también otras normas constitucionales que, no teniendo espacio formal en su cuerpo, sí lo tienen materialmente. Así, la Constitución del Estado en el derecho contemporáneo no debe entenderse solamente desde el punto de vista formal, es decir, desde su literalidad y forma, sino desde su materia y esencia. En esta perspectiva, la Constitución material se conforma por todas las normas que, sin estar presentes expresamente en el texto, son parte y tienen la misma fuerza constitucional. Ese bloque de constitucionalidad irradiará en adelante a todo el derecho, por ende constitucionalizará el mundo de la vida social (fenómenos políticos, éticos y culturales).

Para la Escuela genovesa, la constitucionalización es un proceso mediante el cual la Constitución, como norma suprema, ha invadido el derecho y otras realidades, haciendo que todo lo que está bajo su poder se encuentre constitucionalizado. En los términos de Guastini (2003), la constitucionalización del derecho es:

[...] un proceso de transformación de un ordenamiento al término del cual el ordenamiento en cuestión resulta totalmente "impregnado" por las normas constitucionales. Un ordenamiento jurídico constitucionalizado se caracteriza por una Constitución extremadamente invasora, entrometida (pervasiva, invadente), capaz de condicionar tanto la legislación como la jurisprudencia y el estilo doctrinal, la acción de los actores políticos, así como las relaciones sociales. (p. 49)

En esa misma línea argumentativa, Comanducci señala que la constitucionalización es un fenómeno en el que la Constitución ha desplegado todo su poder para subordinar gradualmente al derecho. En este sentido, la Carta Fundamental no es una norma más que conforma lo que se conoce como ordenamiento jurídico del Estado, sino la norma superior que ha colonizado el derecho y la actividad de los actores políticos:

Se trata de un proceso al término del cual el derecho es "impregnado", "saturado" o "embebido por la Constitución: Un derecho constitucionalizado se caracteriza por una Constitución invasiva, que condiciona la legislación, la jurisprudencia, la doctrina y los comportamientos de los actores políticos. (Comanducci, 2003, p. 86) 
El autor hace énfasis, además, en que la constitucionalización es un concepto que no está del todo definido y que está por construirse. Lo viejo, lo nuevo y lo que está por venir queda determinado por su poder.

A su turno, Barberis (2003) afirma que la constitucionalización del derecho ha llegado a tal punto de desarrollo que ha permeado varios sistemas de derecho, promovido básicamente por tribunales constitucionales que, a la par de los planteamientos de los estudiosos del derecho, han logrado establecer la esencia misma de la Constitución y su finalidad. La constitucionalización del derecho, según afirma Barberis:

[...] no afecta solamente a Italia, sino a todas las grandes democracias occidentales, con la única y parcial excepción de Inglaterra. Es conocido, por ejemplo, el papel central desempeñado por el tribunal Supremo en el sistema jurídico-político estadounidense: papel que explica por qué la tesis del jurista Dworkin como las del filósofo John Rawls se resuelven cada vez más en argumentos que se dirigen a los tribunales. Igualmente, conocido es el activismo del Tribunal Constitucional alemán, que desde finales de los años cincuenta no pierde ocasión de lamentar "el estrecho positivismo legalista" y/o un "positivismo legalista de carácter neutral hace tiempo superado"; incluso el Consejo Constitucional francés, en la patria del "positivismo legalista", ha asumido un papel bastante importante a la hora de promover el debate sobre la constitucionalización del Derecho francés. (2003, p. 262)

Barberis al tiempo que resalta la capacidad de irradiación que ha tenido el fenómeno de la constitucionalización en diversos sistemas de derecho, destaca el papel de los tribunales constitucionales en este proceso. El papel de los jueces constitucionales ya no se limita a resolver cuestiones formales frente a la Constitución, ahora su labor es más importante: desarrollar y materializar el contenido dogmático de la misma.

De otro lado, el proceso de constitucionalización supone la presencia de dos elementos fundamentales: por una parte, de un objeto activo con el suficiente imperio para someter todo lo que está bajo su órbita, y por otra, de objetos y sujetos pasivos que son proclives a la dominación. El primer objeto es la Constitución, el segundo, en forma particular es el derecho y en abstracto el mundo de vida social. Desde esta perspectiva, no se está hablando solamente de una constitucionalización del derecho, sino de la constitucionalización de la vida misma. Así, como una diosa, la Constitución hace presencia en todas partes (ubicuidad), determinando todo a su paso y elaborando su propio mundo.

Guastini entiende que la constitucionalización es un proceso constante, inacabado, que puede medirse según los "grados" alcanzados en ese proceso. Por esta razón no puede decirse que el derecho de un Estado está o no completamente constitucionalizado, ya que puede desarrollarse en ciertas materias, en distintos grados y con variada intensidad. Lo que los Estados constitucionales pueden mostrar sin caer en exageraciones son los avances o retrocesos, más no un resultado definitivo, pues, como en todo proceso, pueden presentarse tanto avances o retrocesos. En palabras del autor:

Sin embargo, antes de proceder, deseo señalar que el concepto de constitucionalización, como yo lo entiendo, no es un concepto bipolar (verdadero o falso), de forma que un ordenamiento únicamente puede estar constitucionalizado o no estarlo en absoluto, sin algún punto intermedio. Más bien sostengo que la constitucionalización es una cuestión de grado, en el sentido de que 
un ordenamiento puede estar más o menos constitucionalizado. Y esto depende de cuántas y cuáles condiciones de constitucionalización estén satisfechas en el seno de aquel ordenamiento. (Guastini, 2003, p, 50)

De lo señalado por el autor se concluye que los ordenamientos jurídicos no están del todo constitucionalizados, es entendible que así sea por la dificultad que representa, sobre todo teniendo en cuenta que dentro de los ordenamientos jurídicos este proceso encuentra resistencia. Autoridades y operadores jurídicos aun cuando conocen su significado no entienden la importancia de la constitucionalización. Teniendo en cuenta estas dificultades, el reto es lograr que la presencia de la Constitución afecte con la misma fuerza y con la misma intensidad. En otras palabras, el "deber ser" de todo sujeto, acto y voluntad es su constitucionalización.

La constitucionalización del derecho refiere entonces tanto a un proceso como a un resultado. En cuanto a éste, dicho fenómeno debe entenderse como la afectación sobre toda realidad que ha podido alcanzar. Muestra de ello es que la Constitución se reserva el derecho de admitir y excluir normas del ordenamiento jurídico, es decir, actúa depurando y armonizando el sistema como un mecanismo de autodefensa. Como proceso, la Constitucionalización del derecho es una instancia inacabada, continua y constante (Guastini, 2003), por lo que necesita de un tiempo y de un espacio amplio para desarrollarse. El tiempo es el necesario para que la norma fundamental logre adentrarse hasta en la esencia misma de las cosas; el espacio es un lugar que no es un lugar geográfico, sino más bien un mundo vital.

De esa forma, la constitucionalización del derecho señala una nueva ruta para que transite el derecho. Un "nuevo" derecho producido por el poder de "emergentes" constituciones impera el universo jurídico contemporáneo, fenómeno que a la vez empodera a otros sujetos para buscar una "esperada" justicia. A ese derecho algunos lo llaman "neoconstitucionalismo(s)", o simplemente constitucionalismo contemporáneo, para evitar distracciones semánticas. En seguida se procede a ilustrar este fenómeno en la figura 1:

Figura 1. El proceso de constitucionalización

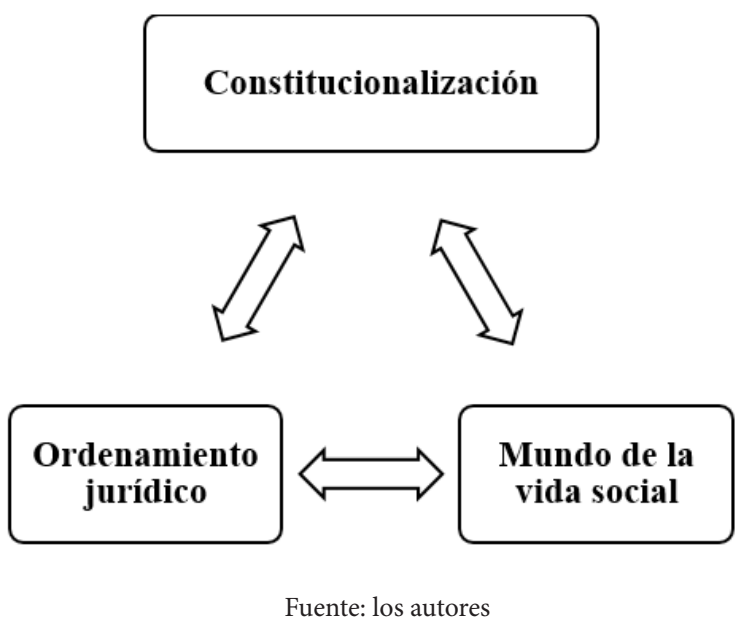


De lo anterior puede extractarse, igualmente, que los procesos contemporáneos de constitucionalización del derecho imprimen una fuerza vinculante a los valores y principios fundantes del Estado constitucional y democrático de derecho, en torno a pretensiones axiológicas mayores que las evidenciadas cuando las decisiones judiciales se tomaban únicamente "bajo el imperio de la ley", pues el concepto de ley ya no solo abarca la expresión de la voluntad de las mayorías legislativas, ejemplo de lo que se denomina "ley en sentido formal", también, comprende elementos como los principios de rango constitucional que introducen paradigmas de mayor relevancia, asociados a libertades, pretensiones materiales de justicia, límites al accionar del Estado, reglas y criterios de acción específicos sobre competencias y atribuciones de las autoridades públicas.

Es decir, la interpretación del "derecho material”, ahora en clave de postulados constitucionales, es un ambicioso plan de subordinación del imperio de la ley a los principios, valores y reglas de la Constitución como fin ulterior de la sociedad democrática. Ferrajoli (2011) llama a este tipo de constitucionalismo "argumentativo o garantista", caracterizado por: "La configuración de los derechos fundamentales como valores o principios morales estructuralmente distintos de las reglas" (2011, pp. 20-21).

Esa resignificación de la vida jurídica ha implicado también un mayor acercamiento de la ciudadanía a sus instituciones constitucionales, otorgando al derecho constitucional una importancia capital a la hora de interpretar las reglas jurídicas contenidas en códigos sistematizados, y que suponen mayores ejercicios de interpretación y articulación de los valores superiores frente a las formas jurídicas puramente procedimentales, ahora absorbidas por presupuestos con especial prevalencia, capaces de ser usados en todos los estadios discursivos del derecho.

Es tal la dinamización del fenómeno, que actualmente el estudio de las principales instituciones constitucionales y políticas del Estado democrático y constitucional de derecho se torna obligatorio para las demás disciplinas académicas, hecho que, sin duda, pone de presente la importancia de las transformaciones de los paradigmas jurídicos, ahora entendidos en torno a la protección y promoción de los valores previstos por el Constituyente, que son, en últimas, los fines perseguidos en la búsqueda de la paz, la justicia, la seguridad jurídica y la democracia misma.

\section{Los efectos de la Constitucionalización del Derecho}

Desde un enfoque consecuencialista, el proceso de constitucionalización del ordenamiento jurídico ha producido fenómenos jurídicos importantes, no solo para el derecho, sino para el pensamiento jurídico, dice García Figueroa. Según este autor, el nuevo carácter que el constitucionalismo ha adoptado para sí es lo que lo distingue del constitucionalismo clásico o tradicional, rompiendo de esa manera -temporal y materialmente- con una visión reducida de la Constitución, para proyectarla a un terreno mucho más fructífero, en lo que en adelante se denominará "neoconstitucionalismo". Afirma el autor:

[...], la constitucionalización del ordenamiento jurídico no se ha limitado a transformar el Derecho, sino que se predica también del estilo de pensamiento de juristas y teóricos del Derecho. La constitucionalización del pensamiento jurídico ha dado lugar al "constitucionalismo". Se ha denominado genéricamente "constitucionalismo" (y más precisamente "neoconstitucionalismo" con el fin de acentuar el nuevo carácter que ha adquirido en la actualidad) a la teoría o conjunto 
de teorías que han proporcionado una cobertura iusteórica conceptual y/o normativa a la constitucionalización del Derecho en términos normalmente no positivistas. (García Figueroa, 2003, pp. 164-165)

Este proceso de constitucionalización, siguiendo los planteamientos de García Figueroa, ha incidido en aspectos que son propios de la Constitución, y en forma más amplia ha afectado el derecho en toda su complejidad. En opinión del autor, la constitucionalización del derecho terminó por afectar ciertos elementos del ordenamiento jurídico y del Estado que por largo tiempo permanecieron blindados de cualquier injerencia. Estos elementos son el i) material, ii) estructural normativo, iii) estructural del poder y iv) funcional.

En seguida se realizará una aproximación conceptual a cada uno de ellos, complementando la visión de García Figueroa con otros teóricos, con el fin de enriquecer el debate conceptual:

2.1 El aspecto material. La constitucionalización del derecho produjo un derecho humanizado: valores, principios, derechos humanos y fundamentales ingresan al mundo del derecho para "re-materializarlo". En la línea de García Figueroa, Luis Prieto Sanchís afirma que la materia de la Constitución la constituyen disposisiones sustantivas y procedimentales:

Rematerialización constitucional, (...) es la incorporación al texto no solo de normas formales, de competencia o de procedimiento destinadas a regular el ejercicio de los poderes y la relación entre los mismos, sino también y sobre todo de normas sustantivas que pretenden trazar límites negativos y vínculos positivos a lo que dichos poderes están en condiciones de decir legítimamente. (Prieto Sanchís, 2013, p. 26)

De esa manera las "nuevas" constituciones se nutren de un contenido axiológico amplio, abstracto e indeterminado.

Al decir que el contenido de las nuevas constituciones es axiológico, se está haciendo referencia indirecta a la moral, insumo que logró evadir las barreras que el positivismo había construido para posicionarse como un parámetro constitucional, que en adelante validará en términos de justicia las normas del ordenamiento jurídico, así como su interpretación y aplicación. "Se trata de un positivismo moralizado, de un relanzamiento del vínculo entre derecho y moral, cortado por el positivismo jurídico que concibe la realización de los derechos fundamentales y que de antemano promete la práctica de las garantías atribuidas a la dignidad humana" (Waldron, 2011, pp. 108-109).

2.2. El aspecto estructural normativo. Es necesario establecer las diferencias que existen entre las reglas y la Constitución en cuanto a sus estructuras. Básicamente las reglas están conformadas de dos supuestos: el primero es el fáctico, en el cual se subsume el hecho real; el segundo es el jurídico, el cual subsume la consecuencia del hecho ${ }^{1}$. En cambio los principios tienen una estructura abstracta, que genera un campo de interpretación amplio respecto a las reglas y estrecho respecto a los valores. Esto hace que los principios, como lo dice Waluchow: "Son idóneos en disciplinar todo el ordenamiento jurídico de modo que nada queda fuera de su discernimiento deóntico" (1994, p. 44).

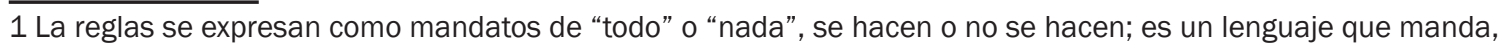
que ordena. 
2.3. El aspecto funcional. Los principios, como se señaló, gozan de una estructura diferente, por lo que su aplicación requiere de un método alternativo, diferente al utilizado por las escuelas formales del derecho. Moreso aborda esa diferencia de la siguiente manera:

La aplicación del derecho suele concebirse como una actividad consistente en determinar la norma individual que establece una cierta consecuencia normativa para un caso individual determinado. Para tal fin, se trata de demostrar que dicho caso individual es una instancia de un caso genérico al que una norma jurídica aplicable correlaciona con esa consecuencia normativa. A dicha operación se le conoce con el nombre de subsunción.

Sin embargo, cuando se trata de la aplicación de los principios constitucionales (...), se argumenta, a veces, que la operación de la subsunción no es adecuada y que debe sustituirse por otra operación denominada ponderación. Es más, suele considerarse que la ponderación es uno de los rasgos centrales de la aplicación del Derecho en la cultura del constitucionalismo. (2003, pp. 99-100)

De esa forma la subsunción es desplazada por un razonamiento complejo llamado ponderación, método que demanda un mayor esfuerzo para precisar su contenido. Necesario es, entonces, que la ponderación se sirva de la hermenéutica jurídica y de una "teoría estándar de la argumentación jurídica", con la cual se pretende mostrar que a partir de la justificación de un razonamiento (moral) puede obtenerse una decisión jurídica en el caso concreto.

2.4. El aspecto estructural del poder. Como lo precisa García Figueroa, la consecuencia: "Más importante consiste en la acentuación del desplazamiento del protagonismo desde el Legislativo hacia el Judicial" (2003, p. 167). El poder legislativo había tenido ese papel desde finales del siglo XVIII hasta finales del siglo XX, etapa en la que la ley se erigía como el instrumento supremo y cuya finalidad era garantizar las libertades individuales, y que siendo producto de la razón general no podía desestimarse, menos vulnerarse. En ese escenario el legislador, poder encargado de crear la ley, se superponía a los demás estamentos, justificando su omnipotencia en su origen popular.

Así, frente a un poder político supremo, inflexible y pleno, pero incapaz de salvaguardar los derechos humanos y fundamentales, el poder judicial logra cobrar autonomía y reclama para sí la labor que el poder legislativo no pudo cumplir: la eficacia de dichos derechos. A continuación se ilustra el anterior contenido en la figura 2: 
Figura 2. Efectos del proceso de constitucionalización según Alfonso García

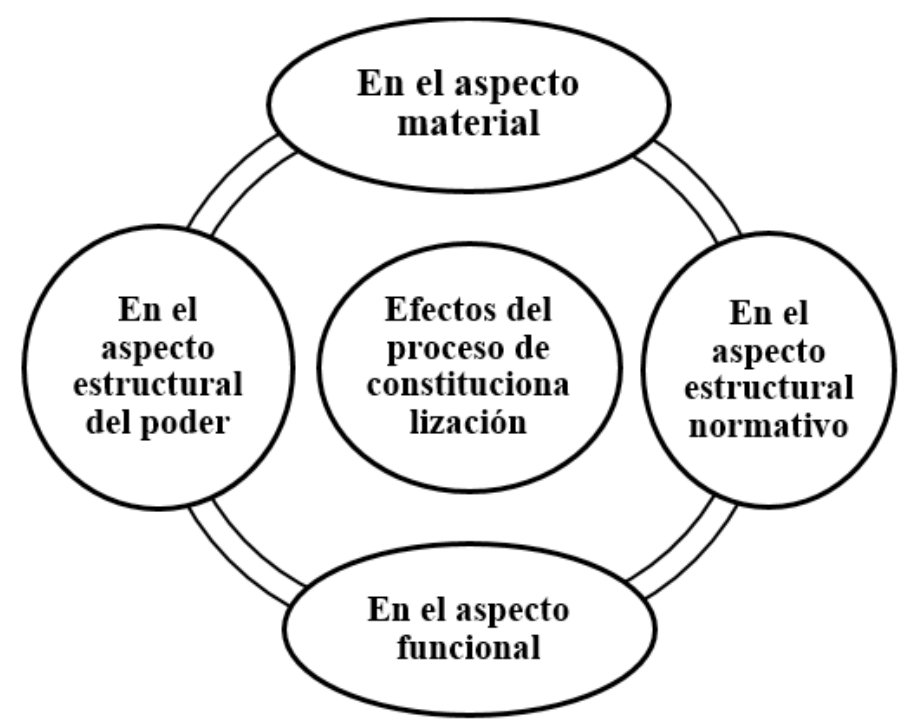

Fuente: los autores

Ahora bien, uno de los presupuestos más relevantes de este fenómeno lo constituye la redefinición de los contenidos programáticos del sistema jurídico, en torno a presupuestos tales como el reconocimiento de las diversidades, las diferencias y la ampliación de los derechos individuales y colectivos, inclusive de aquellos que cuentan con altos componentes de carácter económico o prestacional, incluyendo a su vez, muchos aspectos progresistas frente a ordenamientos jurídicos tradicionales, como las autonomías territoriales y demográficas y los reconocimientos de las multiplicidades de formas de justicia, como las justicias alternativas, la creación de nuevas formas de identidad en torno a las diferentes ciudadanías y los grupos humanos que son destinatarios de las normas, por supuesto, reivindican muchas más pretensiones de justicia material que las que el sistema tradicional podía brindarles, tal como señala el profesor Uprimny a propósito de las transformaciones de los sistemas constitucionales en América Latina durante el boom del llamado neoconstitucionalismo (Uprimny, 2011).

En esta medida, es evidente que el proceso de transformación del modelo jurídico, en clave de constitucionalización del derecho, supera las barreras de la igualdad formal ante la ley, como la metáfora del cuento clásico de Kafka, para entrar a repotenciar las relaciones de los ciudadanos ante su sistema jurídico, sus autoridades públicas y sus pretensiones reales y materiales de justicia y de igualdad, ahora vista como pretensión de mayor equidad, en consideración a condiciones objetivas y subjetivas determinantes, aspiración integradora cuyo punto de partida es, sin duda alguna, el espectro constitucional del ordenamiento positivo.

\section{Las condiciones del proceso de constitucionalización en el caso italiano}

En los apartados anteriores se enfatizó en la supremacía constitucional y en el proceso de constitucionalización del derecho y del mundo de la vida social, así como en las consecuencias de ese proceso. Partiendo de ese punto, en seguida se analizarán las condiciones del proceso de constitucionalización en Italia. Por su importancia para el tema, es necesario 
abordar detenidamente cada una de ellas, con el objeto de identificar los rasgos principales y sus efectos en el proceso de constitucionalización. Hay que aclarar que las condiciones de constitucionalización del caso italiano que se toman como referencia tienen como fuente la obra de Guastini (2003).

3.1. Una Constitución rígida. Rígida en el entendido que el procedimiento para su reforma es más complejo que el procedimiento para reformar una ley. La Constitución debe ser una norma estable y esa estabilidad se asegura afirmando un procedimiento complejo para su reforma; sin embargo, esa rigidez no debe ser tal que no permita poner en consonancia el texto constitucional con la realidad imperante. Lo que se pretende es, como se trata de actualizar la norma más importante del Estado, que se construya un escenario favorable para la discusión: un debate político más profundo, extenso y responsable será la garantía de la reforma válida. Con ello puede evitarse que por la premura y el debate débil terminen no reformando sino sustituyéndola.

La Constitución italiana de 1947, vigente, es uno de los ejemplos de rigidez, pues como lo señala Guastini: "Contiene algunos principos que no pueden ser subvertidos o modificados en su contenido esencial, ni siquiera mediante revisión constitucional (Corte Const. 1146/1998)" (2003, p. 58). Esto quiere decir que la Carta italiana tiene algunas cláusulas que la doctrina denomina pétreas.

3.2. La garantía jurisdiccional de la Constitución. La norma fundamental del Estado debe ser defendida y protegida de las amenazas y de los ataques provenientes de los poderes del Estado y de sus autoridades, así como de los particulares cuando estos infringen derechos constitucionales. En principio el poder judicial en cabeza del Tribunal constitucional tiene la competencia para garantizar la integridad y la vigencia de la Constitución. Sin embargo, los sistemas constitucionales contemporáneos han establecido que dicha potestad no debe concentrarse solamente en los jueces, ya que la defensa y la garantía de la carta debe abrirse a otras autoridades ${ }^{2}$ por ser un tema de interés general.

La jurisdicción constitucional está confiada en la Corte Constitucional italiana y en los jueces comunes. A ellos se le encarga la tarea de defender la integridad de la Constitución. La Corte como lo indica Guastini, ejerce un control "a posteriori, in concreto y por vía de excepción” (2003, p. 58). Los jueces comunes actúan como "filtros" de causas serias que ameritan pasar a la Corte para revisión. Es en realidad un control preliminar de formalidades y contenido.

3.3. LafuerzavinculantedelaConstitución. Su fuerza proviene desu carácter normativo (prescripciones), de tal manera que deja de ser simplemente un manifiesto político de carácter aspiracional para erigirse como una norma jurídica del presente, con la capacidad de ejercer coacción sobre cada uno de los elementos del Estado. Esa fuerza vinculante se ejerce en ocasiones directamente, como en el caso de los principios y los derechos fundamentales; estas normas no necesitan de norma intermedia para poder aplicarse, aunque a veces la intermediación normativa puede ser conveniente.

De ese modo, la Constitución italiana irradia todo el ordenamiento jurídico y lo determina, así como perfila toda realidad que requiere de una solución, sea directamente o por autorización de

2. Cfr; Pero no debe ocultarse el papel de las demás autoridades del Estado al momento de desarrollar su actividad, pues ellas, si hacen su trabajo a la luz de la Constitución, también la están haciendo eficaz. 
la Carta. En ese orden es una norma por antonomasia vinculante. No solo las normas preceptivas tienen fuerza vinculante, también la tienen las normas programáticas, por lo que: "Una ley es inconstitucional no solo cuando contradice directamente una norma preceptiva, sino también cuando entra en conflicto con un principio o con una norma programática" (Guastini, 2003, p. $60)$.

3.4. La "sobre-interpretación" de la Constitución. Ante la interpretación insuficiente que el método literal proporciona para solucionar las controversias de alcance constitucional, las autoridades tienen que acudir a otros métodos de interpretación que mejor se identifiquen con el sentimiento y la emocionalidad de la Constitución. La escogencia de tal o cual método de interpretación dependerá del grado de complejidad de la controversia, así como de la postura interpretativa que adopten los intérpretes autorizados.

En ese estado de cosas, la sobreinterpretación tiene que ver con la búsqueda de un significado que no es el que se deriva de la literalidad de la norma superior, sino el que mejor desarrolle su esencia. "La sobre interpretación de la Constitución es, en Italia, una práctica constante de la Corte Constitucional, de los órganos del Estado en general y de la doctrina. Son innumerables las normas no expresas que han sido extraídas del texto constitucional" (Guastini, 2003, p. 61).

3.5. La aplicación directa de las normas constitucionales con la finalidad de moldear las relaciones sociales. En consonancia con los numerales 2 y 3 , la Constitución puede ser aplicada directamente con el fin de dar una respuesta a los retos que la sociedad impone. Este atributo es una responsabilidad del juez constitucional, autoridad que tiene la potestad en casos de vacíos o defectos normativos de aplicar directa y enteramente las disposiciones constitucionales al caso que lo amerita:

Es lícito sostener que la aplicación jurisdiccional de la Constitución consiste-al menos en resumidas cuentas- en juzgar la legitimidad constitucional de las leyes, lo cual, en el ordenamiento italiano, es competencia exclusiva de la Corte Constitucional. Y por esta razón, la Constitución no puede ser aplicada directamente por los jueces comunes. Sin embargo, en la práctica de los organos jurisdiccionales, las cosas ocurren de otra manera. (Guastini, 2003, p. 67)

3.6. La interpretación conforme de las leyes. Nuevas visiones sobre el derecho y la Constitución son las que promueven la interpretación conforme. Está dirigida a la concreción de la eficacia interpretativa y de la eficacia material de la Carta. Toda norma debe, para su aplicación, interpretarse de conformidad con ella, pues solo eso puede asegurar que la solución dada por la autoridad sea considerada como una solución válida y posiblemente justa. En otros términos, los operadores jurídicos deben buscar validar su interpretación y la decisión en la Constitución.

En el constitucionalismo italiano, la cláusula de interpretación se convierte por esa razón en un canon hermenéutico fiable para interpretar el ordenamiento jurídico en función del contenido dogmático. La interpretación conforme o adecuadora, señala Guastini: "No es únicamente obra de la Corte Constitucional: es practicada también por los jueces comunes (2003, p. 66).

3.7. La influencia de la Constitución sobre las relaciones políticas. Dicha influencia depende de varios elementos: el contenido de la Constitución, la postura de los jueces y de los órganos constitucionales, así como de los actores políticos. Conocido es que la Constitución en el Estado constitucional no solamente contiene y moldea relaciones jurídicas, también es capaz de abordar relaciones morales y políticas con el mismo alcance. En ese orden de ideas, los actores políticos 
y demás actores deben actuar en consonancia con la Carta política para que su actividad se acepte como constitucional, pues si no lo hacen o lo hacen de una forma no autorizada estarían vulnerando los mandatos constitucionales.

Desde 1975, la Corte ha tenido ocasión de juzgar una cantidad notable de conflictos, en los cuales han estado implicados, entre otros, numerosos órganos jurisdiccionales (...), comisiones parlamentarias (...), el Parlamento en su conjunto, el Presidente de la República, el Gobierno en su conjunto así como el Presidente del Consejo, la Corte de Cuentas, el Ministro de Justicia, el Consejo Superior de la Magistratura, el Ministerio Público, y hasta el comité promotor de un referéndum abrogatorio, considerado como expresión del cuerpo electoral. (Guastini, 2003, p. 69)

Las anteriores condiciones de constitucionalización del derecho que describe Guastini permiten comprender la complejidad de ese fenómeno constitucional. La constitucionalización del derecho supone, según esa visión, una pluralidad de cualidades inherentes a la Constitución, que muestran su poder para expandir su alma más allá de su cuerpo, inclusive llegando a tocar realidades no necesariamente jurídicas, como la moral y la política, por ejemplo.

\section{Las condiciones del proceso de constitucionalización del derecho en Colombia}

Las condiciones del proceso de constitucionalización se pueden clasificar en i) sustanciales y ii) procedimentales. Las primeras corresponden a un catálogo de derechos y garantías que conforman el cuerpo constitucional abstracto e indeterminado en el que se pueden contar, por ejemplo, valores, principios y derechos de todo tipo. Las segundas (procedimentales) son las condiciones-cualidades, entre las que se pueden relacionar, sin pretender agotarlas en estas líneas, las siguientes: a) supremacía y rigidez constitucional, b) defensa de la Constitución, c) fuerza vinculante, d) aplicación directa del texto constitucional, y d) la presencia de un canon hermenéutico esencial.

Teniendo como referente el caso italiano, el propósito de este apartado es precisar las condiciones de constitucionalización en Colombia, con el fin de determinar el alcance de cada una de ellas. Veamos:

4.1. Supremacía y rigidez constitucional. En el artículo 4 de la Constitución colombiana de 1991 se establece la supremacía constitucional en los siguientes términos: "La Constitución es norma de normas. En todo caso de incompatibilidad entre la Constitución y la ley u otra norma jurídica, se aplicarán las disposiciones constitucionales". La Corte Constitucional precisó respecto a la supremacía constitucional lo siguiente:

El principio de supremacía constitucional tiene una función jerárquica, lo cual conlleva dos consecuencias. En primer lugar, implica la imposibilidad de predicar en el orden jurídico normas que tengan un nivel superior a la Constitución. Esto implica, a su vez, que aquellas normas que hacen parte del bloque de constitucionalidad en sentido estricto, en los términos del inciso primero del artículo 93 C.P., alcancen el mismo nivel jerárquico de la Constitución, pero no una escala superior que la subordine, por lo que son disposiciones integradas más no superpuestas a la Carta Política. La segunda faceta de la función jerárquica es la de servir de parámetro para la validez formal y material de las normas que integran el ordenamiento jurídico. (Sentencia C-054 de 2016) 
Además de la función jerárquica, la supremacía constitucional tiene una función directiva e integradora. La primera tiene que ver con la orientación de la interpretación de las normas; la segunda se relaciona con la unidad del ordenamiento jurídico, de tal forma que exista una coherencia interna del ordenamiento jurídico en su conjunto.

Aquí debe entenderse la norma superior desde el punto de vista material, es decir, teniendo como referente al conjunto de disposiciones que conforman el bloque de constitucionalidad.

Por su parte, la rigidez constitucional no significa que la Constitución como norma suprema no permita su reforma, pues como lo ha dicho la Corte Constitucional en su variada jurisprudencia, ninguna disposición consagra cláusulas pétreas o inmodificables. Teniendo claro esto, la rigidez constitucional está del lado de la estabilidad constitucional, de modo tal que permite su reforma mediante actos complejos que procuren un mayor debate democrático. La Constitución colombiana establece así tres posibilidades de reforma constitucional: por el Congreso mediante acto legislativo, el pueblo directamente a través de Referendo y por una Asamblea Nacional Constituyente (art. 374). Cualquiera que sea el procedimiento de reforma se debe evitar a toda costa una eventual sustitución de la Constitución. El papel de la Corte Constitucional en esta tarea ha sido fundamental.

4.2. La garantía jurisdiccional y pública de la Constitución. El sistema de control que adoptó el constitucionalismo colombiano fue el control mixto de constitucionalidad. En este sistema coexiste el control concentrado y el control difuso. El concentrado es responsabilidad de la Corte Constitucional según lo indica el artículo 241 constitucional. El difuso en cambio es responsabilidad de los jueces, autoridades administrativas y particulares en ejercicio de funciones públicas.

En esos términos se pronuncia la Corte Constitucional en la sentencia C-122 de 2011:

[...] nuestro sistema de control de constitucionalidad se ha calificado por la doctrina como un sistema mixto ya que combina un control concentrado en cabeza de la Corte Constitucional y un control difuso de constitucionalidad en donde cualquier autoridad puede dejar de aplicar la ley u otra norma jurídica por ser contraria a la Constitución. De otra parte hay que tener en cuenta que el control por vía de excepción lo puede realizar cualquier juez, autoridad administrativa e incluso particulares que tengan que aplicar una norma jurídica en un caso concreto. Este tipo de control se realiza a solicitud de parte en un proceso judicial o ex officio por parte de la autoridad o el particular al momento de aplicar una norma jurídica que encuentre contraria a la Constitución. (Sentencia C-122 de 2011)

El control de constitucionalidad concentrado puede ser oficioso o a través de la acción pública (art. 40), según la norma en cuestión. Si la Corte llega a la conclusión de que la norma bajo control es contraria a la Constitución declarará su inexequibilidad, y el efecto será erga omnes. Por su parte, el control difuso de constitucionalidad se realiza mediando solicitud de parte o también de forma oficiosa. Este control se realiza, por ejemplo, en conocimiento de acción de tutela y habeas corpus, en ejercicio de la excepción de inconstitucionalidad y por los tribunales administrativos cuando conocen de demandas de nulidad de normas territoriales. En las primeras el efecto es inter partes; en el caso de nulidad declarada por los tribunales el efecto será erga omnes, pero solo en la circunscripción territorial.

4.3. La fuerza vinculante de la Constitución. La norma fundamental colombiana no es solo una carta política; pues es, además, una norma y como tal posee una fuerza jurídica que es capaz de 
incidir directamente en el ordenamiento jurídico. En este sentido, la Corte Constitucional ha reiterado que las normas constitucionales tienen la fuerza suficiente para determinar la actividad jurisdiccional:

La fuerza vinculante de las normas constitucionales se irradia también a todo el ámbito del resto de la actividad jurisdiccional. Si bien el juez natural en las jurisdicciones ordinaria y contencioso administrativa debe aplicar la ley respetando la jerarquía de las normas que emana de la Carta, lo cual le impone descartar aquellas que resultan inarmónicas o contradictorias con las superiores, debe hacerlo permitiendo que los valores superiores permeen la interpretación y aplicación de las normas. La Constitución tiene un impacto directo sobre todo el resto del orden jurídico, que impone a cualquier juez el fallar realizando, es decir haciendo efectivos en el plano de los hechos, los principios y valores contenidos en la Constitución, especialmente los enunciados en el artículo $2^{\circ}$ superior. (Sentencia C-037 del 2000)

Lo anterior supera el clásico modelo positivista que obligaba al legislador a desarrollar los postulados y principios constitucionales por intermedio de leyes, que muchas veces eran insuficientes a la hora de abordar las pretensiones reales de justicia demandadas por los ciudadanos. El desarrollo de este atributo es más fácil identificarse cuando están en juego los derechos fundamentales, derechos que ante la ausencia de normas positivas y con ayuda del juez constitucional son aplicados directamente.

4.4. La "sobre-interpretación" de la Constitución. La Constitución de 1991 consagró en su cuerpo normas distintas a las reglas, por lo que se hizo necesario acudir a métodos de interpretación emergentes que ayudarían a encontrar el significado de la Constitución. El método tradicional de interpretación ya no era suficiente, nace por tanto la necesidad de descifrar las normas constitucionales, abstractas por antonomasia. Valores y principios son muestra de este tipo de normas.

Es en esa medida que los amplios catálogos de derechos fundamentales que hacen parte de la llamada Constitución dogmática, no solo se miran como unos principios o propósitos ulteriores de la sociedad: "Sino que van a ser considerados como normas jurídicas de obligatorio acatamiento por las instituciones públicas e incluso por los particulares" (Jaramillo, 2001, p. 32), por lo que al ser normas jurídicas vinculantes, se hacen exigibles y son reclamables, se convierten en los primeros criterios de interpretación de la actividad pública y, en particular, la actividad jurisdiccional. Solo de esta forma se puede entender la importancia y el impacto que tienen las decisiones progresistas de los jueces a la luz de la Constitución, ya no como un catálogo de buenos principios, sino como un poder vinculante y determinante que permite a la sociedad contar con instrumentos de eficacia para su materialización.

4.5. La aplicación directa de las normas constitucionales con la finalidad de moldear las relaciones sociales. Diversos son los ejemplos en los que la Constitución ha desplegado su poder con el fin de solucionar directamente controversias sociales que el derecho positivo olvidó. La Corte Constitucional de Colombia, aplicando directamente la Carta, cambió positivamente realidades que hasta el momento carecían de protección jurídica. En ese sentido protegió la diversidad étnica, a las víctimas del conflicto armado, estableció el mínimo vital, permitió la eutanasia y la interrupción del embarazo, reconoció derechos a la población LGTBI y últimamente sus fallos en relación con la Justicia Especial Para la Paz han mostrado el impacto positivo de la Constitución en la sociedad. 
4.6. La interpretación conforme de las normas. La exigencia de la materia que nutre la Constitución imponía la adopción de criterios, métodos y parámetros de interpretación ${ }^{3}$. De esa manera, la interpretación conforme, el principio pro homine, la ponderación, entre otros métodos, ayudan en la labor constitucional. "La interpretación conforme establece en ese sentido: i) la adecuación o la actualización de las normas constitucionales según los tratados de derechos humanos; ii) la complementariedad de los sistemas y; iii), la observancia del principio pro persona" (Zeballosf, 2016, p. 177).

Haciendo referencia al principio pro homine, el alto tribunal señaló:

El principio pro homine es un criterio hermenéutico que informa todo el derecho de los derechos humanos, en virtud del cual se debe acudir a la norma más amplia, o a la interpretación más extensiva, cuando se trata de reconocer derechos protegidos, e inversamente, a la norma o a la interpretación más restringida cuando se trata de establecer restricciones permanentes al ejercicio de los derechos o a su suspensión extraordinaria. Este principio coincide con el rasgo fundamental del derecho de los derechos humanos, esto es, estar siempre a favor del hombre. (Sentencia T-284 de 2006)

4.7. La influencia de la Constitución sobre las relaciones políticas. La Constitución así como moldea las relaciones sociales moldea y afecta también las relaciones políticas. Con esa fuerza la carta determina dicha actividad, haciendo que se ajuste a los mandatos que ella impone. Por ejemplo, el cuerpo político por excelencia, Congreso de la República, debe enmarcar el ejercicio de sus funciones de conformidad con la norma superior. Lo mismo se esperaría de los cuerpos político-administrativos en el terreno local, cuyo trabajo en el orden territorial debe superar el reto de desarrollar los mandatos superiores.

A nivel más amplio, la Constitución incide en el debate político público, por ejemplo, la discusión en torno a la implementación de los acuerdos de paz, el ejercicio de la protesta social, el alcance de los mecanismos de participación, la tributación, entre otros. En conclusión, todas las dinámicas políticas son susceptibles de irradiación constitucional, como se ilustra en la figura 3:

En su ya clásica obra El Derecho de los Jueces, Diego López señaló a propósito de la transformación de los paradigmas constitucionales, que el papel del operador jurídico se torna más activo en

Figura 3. Condiciones de constitucionalización en Colombia

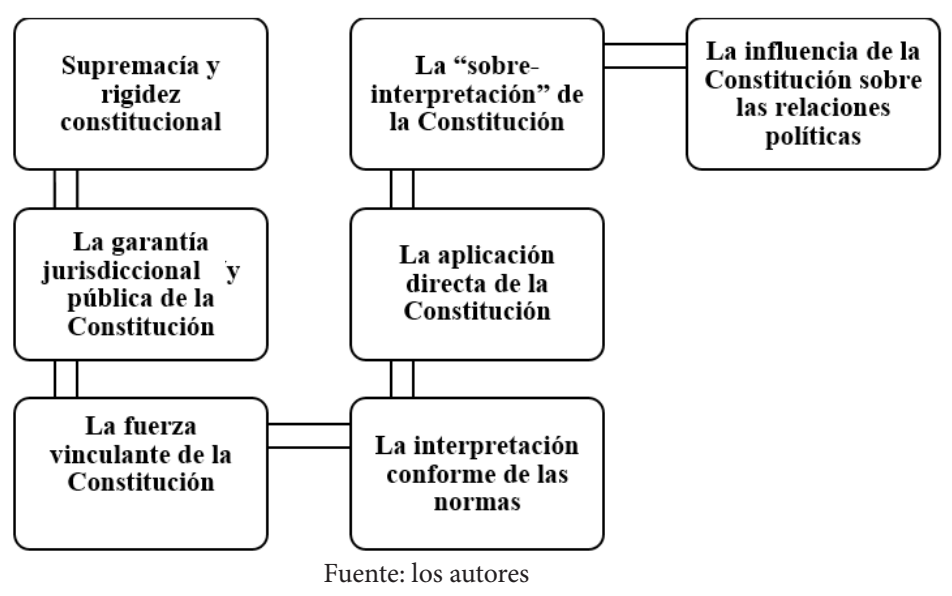


función de la protección de valores ya preestablecidos por el juez constitucional, dado que: "La doctrina constitucional (...) tiene fuerza gravitacional que atrae a todos los demás casos que sean planteados ante los jueces y que sean fácticamente similares al ya decidido por la Corte" (López, 2006, p. 61). En estas condiciones puede sostenerse como lo hace López que el proceso de constitucionalización del derecho en Colombia, así como en los demás países que le han apostado a este tipo de modelos supralegales, supone un criterio hermenéutico más calificado a la hora de resolver situaciones sometidas al derecho, en la medida que la toma de una decisión judicial, a la luz de precedentes jurisprudenciales dictados en clave de constitucionalidad, contribuye a la elaboración de análisis e interpretaciones racionales justificados y razonables, que sean compatibles con las decisiones ya ejecutoriadas, aún cuando el operador judicial se aparte de la decisión que le precede, en todo caso justificando su decisión, y demostrando racionalmente que su decisión final se ajusta a parámetros superiores y que se ha llegado a ella a partir de ponderaciones adecuadas fundadas en principios de necesidad, razonabilidad, proporcionalidad y utilidad.

No es un secreto que el proceso de transformación constitucional de 1991, que incorporó los elementos centrales del llamado neoconstitucionalismo o constitucionalismo contemporáneo al espectro jurídico y político colombiano, pretendió ser una bitácora que permitiera establecer las bases para la reducción de la violencia y la búsqueda de un proceso de paz. De ahí que el modelo de la Constitución Política de 1991 fuera vista en sus inicios como el posible instrumento para alcanzar la reconciliación social en torno a principios jurídicos de pretensión universal, como la justicia, la paz, la solidaridad, la equidad, entre otros.

\section{Conclusiones}

Como corolario de lo anterior, se puede advertir que los procesos de constitucionalización del derecho en los Estados contemporáneos no solo ha significado la subordinación del derecho formal a los postulados constitucionales en aras de hacer prevalecer los principios, valores y reglas constitucionales, tales como la justicia, la igualdad real, la solidaridad o la dignidad humana, sino que también supone la entrada en vigencia de un régimen hermenéutico más progresista y avanzado, que permite al operador judicial tomar decisiones sin desconocer garantías mínimas previstas desde el constituyente, y aproximar aún más el contenido material del texto constitucional a las reales pretensiones de justicia.

Los ejemplos de Italia y de Colombia son paradigmáticos en la medida en que el derecho positivo y tradicional se ve obligado a dinamizarse y a ajustar sus reglas a los postulados constitucionales, permitiendo un grado mayor de legitimidad social sobre el escenario normativo, ahora entendido en clave de constitucionalidad, y en función de instrumentos directos e inmediatos de defensa de los mismos, pues además de los mecanismos directos de protección de derechos fundamentales, previstos en las transformaciones constitucionales de avanzada, se tienen también criterios que permiten a las autoridades públicas abstenerse de aplicar una norma cuando quiera que se pueda advertir que la misma pueda ir en contravía de postulados superiores.

La unidad del ordenamiento jurídico es, sin duda, uno de los grandes retos de las sociedades democráticas que le apuestan al modelo del Estado Constitucional de Derecho, en torno a la figura de la Constitución como marco regulatorio de la vida social y política de un país, de cara a la necesidad de consolidar una adecuada seguridad jurídica. Dicha norma es el sello 
de calidad de una democracia estable que cumple con estándares jurídicos mínimos para garantizar la consolidación de regímenes abiertos, incluyentes, participativos y equitativos, en torno a propósitos comunes determinados como principios rectores. Por tanto, la recopilación que hacen los modernos textos constitucionales de tales valores y presupuestos axiológicos, muy cercanos a criterios morales de carácter universal y de pretensiones de justicia, son presupuestos fundantes en la reconfiguración del ordenamiento jurídico, como máxima apuesta de la constitucionalización del derecho como fenómeno social, político, jurídico y cultural.

Pero la labor es más ambiciosa: para garantizar que el ordenamiento jurídico realmente responda a las expectativas que brinda el andamiaje y la arquitectura constitucional, se requiere también de una decidida intervención y participación de las autoridades públicas, especialmente las jurisdiccionales, para hacer que el papel interpretativo que se refleja en las decisiones administrativas y judiciales corresponda realmente con los postulados de la Constitución.

En igual sentido, la materialización del principio de colaboración armónica entre autoridades públicas exige, a la luz de la Constitución, que sean las autoridades del Estado quienes más propugnen por la defensa de las instituciones constitucionales y la irradiación de sus valores, principios y reglas a todas las actividades en las que se comprometen los intereses públicos y privados, y de la misma manera, se fortalezca el sistema constitucional que tiene carácter imperativo y vinculante, aún en contra de los intereses coyunturales y de turno de las colectividades políticas.

\section{Referencias bibliográficas}

Barberis, M. (2003). Neoconstitucionalismo, Democracia e Imperialismo de la moral. En Carbonell, Miguel (ed.), Neoconstitucionalismos (pp. 259-278). México: Trotta.

Comanducci, P. (2003). Formas de (Neo)constitucionalismo: un análisis metateórico. En Carbonell, M. (ed.), Neoconstitucionalismos (pp. 75-98.). México: Trotta.

Corte Constitucional de Colombia, Sala Plena. (26 de enero del 2000). Sentencia C-037/2000. M.P. Vladimiro Naranjo Mesa. Recuperado de http://www.corteconstitucional.gov.co/ relatoria/2000/C-037-00.htm.

Corte Constitucional de Colombia, Sala Plena. (1 de marzo de 2011). Sentencia C-122/2011. M.P. Juan Carlos Henao Pérez. Recuperado de http://www.corteconstitucional.gov.co/ relatoria/2011/c-122-11.htm.

Corte Constitucional de Colombia, Sala plena. (10 de febrero del 2016). Sentencia C-054/2016. M.P. Luis Ernesto Vargas Silva. Recuperado de http://www.corteconstitucional.gov.co/ relatoria/2016/C-054-16.htm.

Corte Constitucional de Colombia, Sala Plena. (26 de septiembre de 1995). Sentencia T - 425/ 1995. M.P. Eduardo Cifuentes Muñoz. Recuperado de http://www.corteconstitucional.gov.co/ relatoria/1995/T-425-95.htm.

Corte Constitucional de Colombia, Sala Plena. (5 de abril de 2006). Sentencia T - 284/2006. M.P. Clara Inés Vargas Hernández. Recuperado de http://www.corteconstitucional.gov.co/ relatoria/2006/T-284-06.htm. 
Ferrajoli, L. (2011). Constitucionalismo principalista y constitucionalismo garantista. Doxa, Cuadernos de filosofía del derecho, (34), pp. 15-53.

García, J. (1993). La Filosofía del Derecho de Jürgen Habermas. Doxa, Cuadernos de filosofía del derecho, (13), 235 - 258.

García, A. (2003). La teoría del derecho en tiempos de Constitucionalismo. En Carbonell, Miguel (ed.), Neoconstitucionalismos, pp. 159-186. México: Trotta.

Guastini, R. (2003). La constitucionalización del ordenamiento jurídico: el caso italiano. En Carbonell, Miguel (ed.), Neoconstitucionalismos, pp. 49-73. México: Trotta.

Jaramillo, J. (2001). Diálogos de Paz, ¿formas de deliberación pública? En Herrera, Miguel (ed), Modernidades, Nueva Constitución y Poderes Constituyentes, pp. 131 - 135. Bogotá: Universidad Nacional de Colombia.

López, D. (2006). El Derecho de los Jueces. Obligatoriedad del precedente constitucional, análisis de sentencias y líneas jurisprudenciales y teoría del derecho judicial. Bogotá: Legis.

Mejía, O. (2001). Diálogos de Paz, ¿formas de deliberación pública? En Herrera, Miguel (ed), Modernidades, Nueva Constitución y Poderes Constituyentes, pp. 28-34. Bogotá: Universidad Nacional de Colombia.

Moreso, J. (2003). Conflictos entre principios constitucionales. En Carbonell, Miguel (ed.), Neoconstitucionalismos, pp. 99-121. México: Trotta.

Nino, C. (2012). Introducción al Análisis del Derecho. Buenos Aires: Astrea.

Uprimny, R. (2006). El dilema de la interpretación constitucional. Recuperado de: https:// www.academia.edu/18860966/UPRIMNY_YEPES_Rodrigo_El_dilema_de_la_interpretacion_ constitucional_pp_455_464.

Uprimny, R. (2011). Las transformaciones constitucionales recientes en América Latina: tendencias y desafíos. En Garavito, Cesar (ed), El Derecho en América Latina. Un mapa para el pensamiento jurídico del Siglo XXI”, pp. 109 - 137. Bogotá: Siglo XXI Editores.

Waluchow, W. (1994). Inclusive Legal Positivism. Oxford: Clarendon Press.

Waldron, J. (2001). Normative (or ethical) positivism". En Harts Postcript: Essays on the Concept of Law. Oxford: Oxford University Press.

Zeballosf, A. (2016). El Derecho Internacional de los Derechos Humanos. La Justicia Convencional y el rol de los Estados. Revista Alma Mater, (12), 13-53. 